\title{
UMA LECTURA DE LA COLECCIÓN DE GRABADOS DEL MUSEO DE ARTE MODERNO DE BUENOS AIRES
}

\author{
Silvia Dolinko ${ }^{\text {* }}$
}

\section{RESUMEM:}

Este artículo propone una lectura sobre la colección de grabados del Museo de Arte Moderno de Buenos Aires (MAMBA), iniciada en 1960. En esos tiempos, un nuevo grabado tuvo creciente visibilidad en el campo porteño, en un marco de renovación institucional en el que se inscribe la propia conformación y consolidación del museo.A través del análisis de las obras de Antonio Berni, Luis Seoane, Liliana Porter, Juan Carlos Romero particularidades de esa vasta colección gráfica de uno de los principales museos de la Argentina.

\section{PALABRAS-CLAVES:}

Grabado. MAMBA. Colección. Experimentación

\begin{abstract}
:
This article proposes a reading on the collection of prints from the Museum of Modern Art in Buenos Aires (MAMBA), initiated in 1960. At that time, a new engraving was growing visibility in the Buenos Aires countryside, in the context of institutional renewal. that the formation and consolidation of the museum itself is inscribed. Through the analysis of the works of Antonio Berni, Luis Seoane, Liliana Porter, Juan Carlos Romero and Antonio Seguí, among other artists, this paper intends to account then the particularities of this vast collection of graphic one of the leading museums Argentina. tugal, since the nineteenth century.
\end{abstract}

\section{KEY-WORDS:}

Print. MAMBA. Collection. Experimentation

I * Doctora en Historia y Teoría del Arte por la Universidad de Buenos Aires. Investigadora del Conicet. Profesora titular de Arte argentino y americano del siglo XX en la Maestría en Historia del Arte Argentino y Americano del Instituto de Altos Estudios Sociales de la Universidad Nacional de San Martín (IDAES/UNSAM) y docente de Metodología de la Investigación en la Licenciatura en Artes de la Facultad de Filosofía y Letras de la UBA. (silviadolinko@gmail.com). 
En 1968 se llevó a cabo en el Museo de Arte Moderno de Buenos Aires (MAMBA) un concurso de grabado argentino contemporáneo. Dando cuenta de ese convulsionado momento del campo artístico, en el que también esa práctica era sometida a revisiones y experiencias radicalizadas, Hugo Parpagnoli -entonces director del museo- se refería en el catálogo de esa exposición a la particular dinámica de apertura y sujeción técnica del grabado en función de sus límites disciplinares. Parpagnoli planteaba a dicho métier en contraste respecto de la discusión sobre los parámetros de la producción plástica y de la desmaterialización del objeto artístico en esos tiempos; frente a la "muerte de la pintura", planteaba que el grabado:

cada día se difunde más. Es cierto que algunos grabadores se presentan a salones y concursos con obras tridimensionales, móviles y quizá con sonido. Estas son experiencias interesantes que exigen una consideración especial por parte de la crítica pero que no consiguen romper los límites del arte del grabado tal como hizo la pintura con sus propios límites. ¿Por qué? Porque aún en esas experiencias se conserva ya sea la técnica de la incisión ya sea la de la impresión. Esto es esencial para que haya grabado y es, al mismo tiempo, el freno subjetivo y objetivo que tiene el grabado para que la expresión de su mundo sea moderada y reforzada por una rígida disciplina que no cede sus derechos ni aún en las épocas como la nuestra de revisión de todos los valores. ${ }^{2}$

Más allá de la coyuntura específica que mencionaba este texto, cabe señalar que una oscilación entre la experimentación y la revisión de la tradición signó al grabado a lo largo del siglo xx (Dolinko, 20I2). Junto con la práctica de modalidades de impresión históricas - xilografía, aguafuerte, litografía-, la incorporación de otras posibilidades y recursos técnicos redundó en la conformación de una gráfica expandida respecto de los parámetros ortodoxos. La redefinición de búsquedas estéticas y procedimientos en las cíclicas aperturas disciplinares se articularon con una renovada comprensión del grabado como producción autónoma —cristalizada desde mediados de siglo bajo el concepto de grabado original (Dolinko, 2009 b: 165-194) - y con un creciente reconocimiento en el campo artístico.

Manteniendo su característica de imagen impresa que desde su inherente multiejemplaridad posibilita un mayor acceso a la producción artística, la práctica del grabado fue tomando distancia de su tradicional función de ilustración literaria o de propagación de discursos de denuncia social que lo anclaran en un exclusivo discurso figurativo o narrativo, afirmándose como imagen artística tout court: esta obra múltiple era, entonces, un arte moderno (Dolinko, 2009 a). Esta idea del grabado del siglo xx como un arte autónomo en relación con el proceso de su validación simbólica provee una de las claves para la lectura aquí propuesta sobre esta particular colección del MAMBA, que incluye más de un millar de obras.

Desde fines de los años cincuenta se produjo en la Argentina una apertura a la experimentación gráfica en relación con una progresiva legitimación de la disciplina. Un nuevo grabado tuvo creciente visibilidad en el campo porteño, en un marco de renovación institucional (Giunta, 200I) en el que se inscribe la propia conformación y consolidación de este museo. Es significativo, en este sentido, que el núcleo que en 1960 inició la colección de grabados del MAMBA corresponda a la obra de muchos de los artistas argentinos de distintas generaciones que en esos años contribuían a que esta disciplina fuera comprendida en función de su valor como obra gráfica muchas veces heterodoxa respecto de sus, hasta entonces, rígidos códigos técnicos e iconográficos.

2 Hugo Parpagnoli, presentación del Primer Salón Swift de Grabado 1968 (Museo de Arte Moderno, Buenos Aires, septiembre de 1968). 
En este corpus inicial se suceden manchas informales en la obra de Alberto Greco, Zygro o Mabel Rubli, impresiones sin tinta y papeles troquelados en los gofrados de Fernando López Anaya, texturas y gestos expresivos en las estampas de Albino Fernández, Fernando Maza o Alda Armagni, e imágenes abstractas en la gráfica de numerosos artistas contemporáneos. Dominado durante décadas por la figuración narrativa, el grabado incorporó como recurso "válido" a la abstracción geométrica sólo a mediados de los años cincuenta, cuando esta poética resultaba dominante en la valoración de las instancias de consagración del campo local (García, 20I I). Muchas de las obras que integran esta colección de grabados del MAMBA dan cuenta de esas exploraciones en relación con las variables de la geometría, desde las tempranas serigrafías de Manuel Álvarez, Simona Ertan, Sameer Makarius y GregorioVardánega, pasando por las de Clara Ferrari, Jorge González Mir, María Juana Heras Velasco o Juan Melé hasta las más recientes de Irene Weiss o María Suardi.

Incluso a principios de los años sesenta,Víctor Rebuffo, uno de los principales referentes del grabado social en Argentina desde hacía varias décadas, exploraba en sus xilografías con las texturas de la madera y la composición sintética, cuasi abstracta, dominada por el ritmo de formas y líneas como en La vidala del Culampajá, donde en 1961 retomaba su imaginario sobre el noroeste argentino que lo había consagrado décadas atrás. ${ }^{3}$ Junto con Rebuffo, Pompeyo Audivert fue otro de los nombres relevantes dentro de la tradición del grabado en la Argentina, destacado desde los años veinte por su obra demarcada por el sesgo ortodoxo de la disciplina. Sin embargo, a principios de los años sesenta también desarrolló una gráfica experimental a partir de su exploración con nuevos soportes y recursos visuales que en algunos casos redundaron en imágenes informales.

La colección del MAMBA incluye un importante conjunto de estampas de Audivert que abarca una producción de cinco décadas. Este corpus permite dar cuenta de la obra inicial del artista, como las xilografías de mujeres de líneas estilizadas y resolución sintética, las imágenes realizadas para el libro Molino Rojo del poeta Jacobo Fijman (fig. I) —uno de los pocos casos, dentro de esta colección, de grabados destinados a la ilustración literaria-, como así también sus estampas de gran tamaño de la serie delVía Crucis de 1929, hasta llegar a las impresiones policromas de la década del sesenta realizadas a partir de "técnicas mixtas" y lenguajes expresivos cercanos a la pintura gestual del momento. A la vez, cabe destacar dentro de este conjunto de Pompeyo Audivert sus emblemáticas obras de corte social de los años treinta, protagonizadas por figuras macizas resueltas desde una cuidada organización formal a partir del contraste del blanco y negro propio de la impresión en relieve y de una dinámica estructura de tramas lineales, como en el caso del afiche realizado para la revista Unidad, por la defensa de la cultura, órgano de la antifascista Agrupación de Intelectuales, Artistas, Periodistas y Escritores (AIAPE), o en la imagen de un obrero que empuña una maza en el linóleum Nervio (ambos de 1937). Esta última obra fue incluida en la portada del catálogo diseñado por Alfredo Benavídez Bedoya para la exposición El grabado social y político en Argentina, realizada en el MAMBA en 1992. Si a través de la obra de una treintena de artistas -entre los que se contaban Carlos Alonso,Américo Balán, Aída Carballo, Ricardo Carpani, Roberto Páez, Sergio Sergi, Lino Enea Spilimbergo-y desde un amplio recorte cronológico, esa muestra constituyó una significativa revisión sobre el tema del grabado social argentino, ese espacio otorgado en el catálogo a Audivert remarcaba su lugar preponderante dentro de la tradición de la gráfica comprometida en nuestro país.

3 Esta estampa fue una de las primeras incorporadas por Rafael Squirru para la colección de grabados del MAM; el entonces director de la institución la adquirió en ocasión de la retrospectiva de Rebuffo en las Salas de Exposición del Concejo Deliberante de Buenos Aires. "Muestra retrospectiva de Víctor L. Rebuffo", Histonium, Buenos Aires, año XXI, número 267, agosto de 1961. 


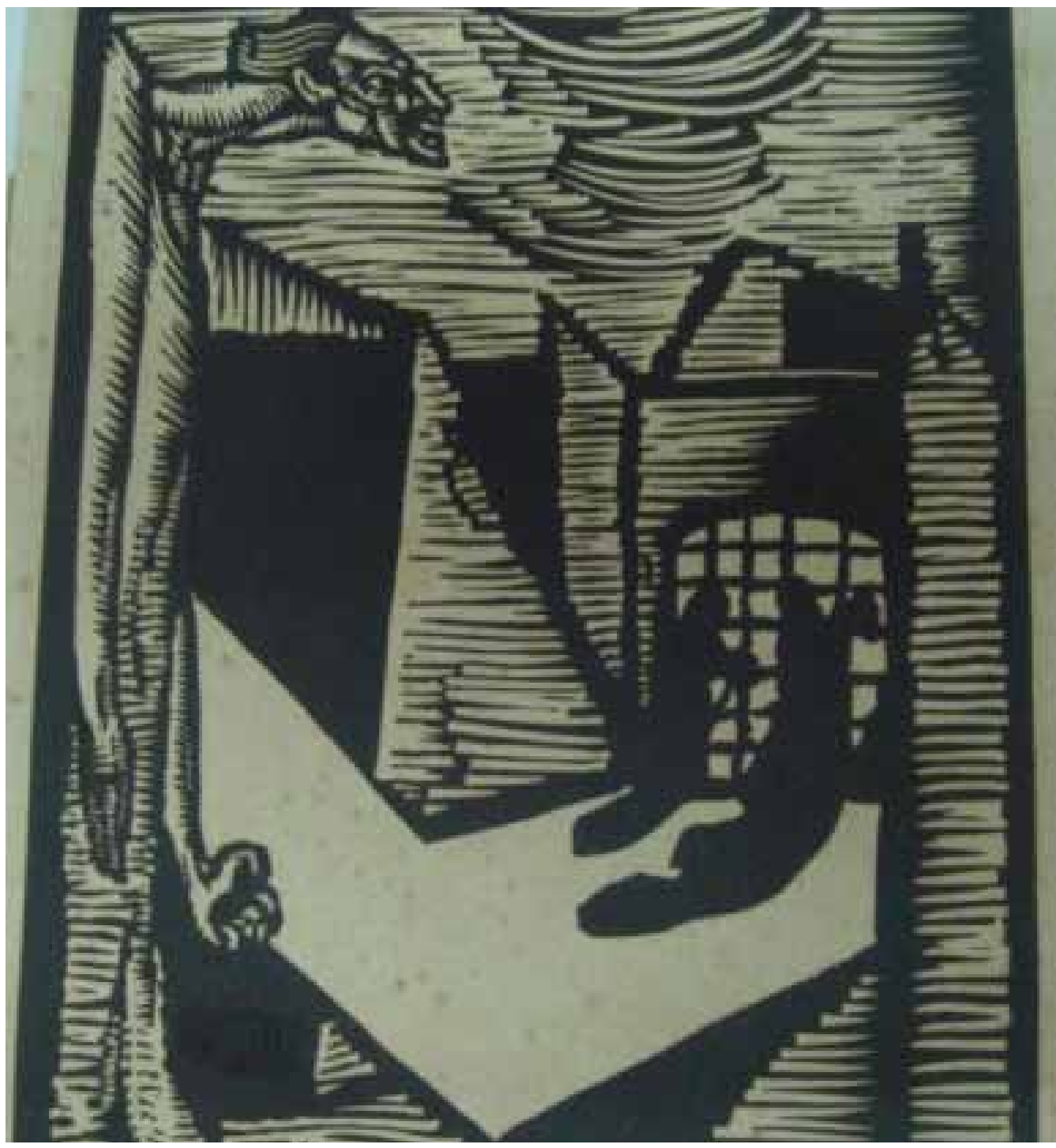

Fig. I. Pompeyo Audivert, Molino Rojo, 1924, fonte: autora.

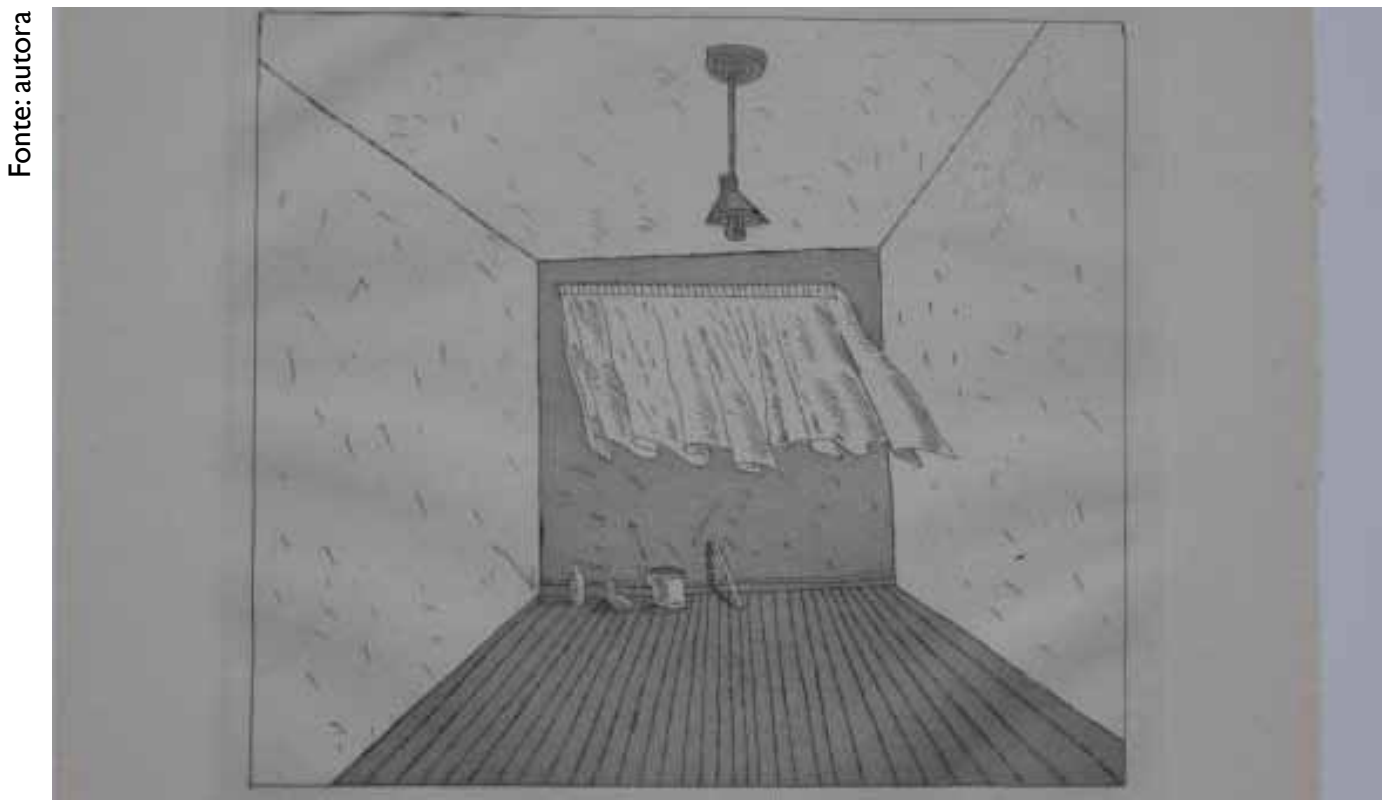

Fig.2. Antonio Seguí, La plaine blanche, aguafuerte-aguatinta, 1978; 
Existen otros dos extensos conjuntos de grabados de artistas argentinos que sobresalen en esta colección: los de Luis Seoane y Antonio Seguí. Ambos, con carreras desarrolladas "de mar a mar" - Seoane entre Argentina y Galicia, Seguí entre Argentina y Francia- en las que desplegaron una vasta producción atravesada por sus respectivas miradas sobre tipos "universales" y prácticas locales; ambos, artistas polifacéticos cuya particular indagación sobre el grabado parte de una similar concepción de la obra seriada, entre el anclaje en las modalidades convencionales y sus ajustes y revisiones en función de la materialización y circulación extendida de una imagen propia.

Las más de cuatrocientas estampas de Seguí que forman parte del patrimonio del MAMBA dan cuenta de su prolífica producción gráfica, al incluir grabados realizados desde 1948 hasta la actualidad. No sólo se trata del más extenso conjunto de obra de un artista que posee este museo - tanto en términos cronológicos como cuantitativos-, sino que constituye la mayor colección de obras de Seguí en una institución. A partir de distintos modos de impresión, el artista multiplica desde hace más de seis décadas su reconocible imaginario sobre el hombre urbano que opera a modo de narración visual sobre personajes y situaciones sociales: un corpus caracterizado por Damián Bayón como un "Castigat ridendo mores (Corrige las costumbres, riéndote de ellas), divisa universal de la comedia humana" (Bayón, 1993).

El impacto del lenguaje de la historieta se pone en evidencia en la obra de Seguí de los años sesenta, en la que se destacan sus aguafuertes sobre militares representados en forma mordaz; allí, la idea de imagen plural que se desprende del grabado aparece implicada en varios sentidos, ya que las figuras de los uniformados no sólo conforman una de las primeras series gráficas del artista, sino que también son multiplicadas dentro de una misma obra:con esta serie dentro de la serie, Seguí alude con trazo caricaturesco a la omnipresente injerencia militar en esos años. También desde mediados de esa década comienza a realizar fotolitografías relacionadas con el pop en términos de su resolución formal y su apelación al imaginario de los medios de comunicación y de la cultura de masas, en las que también inserta personajes de la política del momento. Seguí desarrolla allí una narrativa satírica sobre la sociedad de consumo contemporánea a partir de la articulación de planos de color netos y clisés fotográficos, imágenes de Nixon, Stalin, Kennedy o Mao y sonrientes modelos publicitarias, carteles con distintas tipografías, objetos diversos y tramas geométricas que aluden al op. Muchas de estas obras fueron incluidas en la exposición de setenta dibujos y grabados que Seguí expuso en el MAM en 1972, que dieron cuenta de su producción desarrollada en Francia en esa década.

El humor, el cromatismo brillante y la composición dinámica de la obra de Seguí de los años sesenta muta a mediados de la siguiente década en imágenes más "reconcentradas" de clima enigmático, como en la serie Elefantes en la Pampa, en la que conjuga las pesadas figuras de los animales con un hombre de espaldas, a veces frente a un muro y otras ante la inmensidad de la llanura. También en el conjunto de aguafuertes La plaine Blanche (1977) (fig. 2), entre habitaciones cerradas y planicies vacías, Seguí propone una imagen de la ausencia a partir de una resolución ascética y en blanco y negro. Desde los años ochenta, junto a sus recreaciones del "paisaje humano" cordobés, una gran proporción del corpus gráfico de Seguí está dedicado a sus característicos personajes urbanos multiplicados en situaciones y escenas grupales; en estrecha relación con sus series gráficas, el artista también desarrolla este imaginario en otros soportes por los que transita su obra: pinturas, relieves, afiches. 
Luis Seoane también realizó una vasta obra en la que indagó en distintas modalidades técnicas, aunque se centró especialmente en la xilografía; a la vez, exploró tempranamente con las posibilidades del estarcido y la serigrafía como una particular relectura de las formas populares de multiplicación de imágenes. Su producción apuntó a reformular desde el lenguaje de la modernidad los criterios de representación del imaginario localista gallego y argentino -sus dos horizontes geográficos y culturales-, manteniendo a la vez una activa mirada sobre la cultura occidental en tanto matriz simbólica "universal" (Dolinko, 2006). ${ }^{4}$ En 197I, el MAM organizó una muestra retrospectiva de doscientos grabados de Seoane: después de años de asidua presencia en el circuito de galerías de arte, una institución oficial argentina otorgaba por primera vez un significativo espacio a su obra. ${ }^{5}$ Luego de la exposición, el artista donó al museo los grabados allí exhibidos. Este conjunto incluye desde sus tempranas escenas de tauromaquia de Eh! Los toros (1942) —destacadas en su momento por el escritor Guillermo de Torre por su aporte a la "rehabilitación" de la xilografía- ${ }^{6}$ y las imágenes de líderes gallegos en las luchas populares como Ruy Xordo (1944), hasta sus figuras arquetípicas como el pescador o la campesina, elecciones iconográficas que reafirman algunos aspectos de las raíces populares de la producción de Seoane, interpretadas desde recursos modernos. Asimismo, se encuentran en esta colección sus estarcidos de mediados de los años cincuenta, realizados a partir de sintéticos planos de color saturado y líneas gruesas impresas con témpera. También, sus xilografías experimentales con collage desarrolladas desde fines de esa década.

Junto a algunas composiciones abiertamente abstractas (fig. 3), Seoane representó en estos grabados en madera a mendigos, guerreros, hechiceras, danzarinas o gauchos, entre otras figuras. Al recurrir a un lenguaje formal sintético que articulaba colores, texturas y elementos diversos agregados a la madera de base para la impresión (como bandas de cinta adhesiva y pegamento sintético), Seoane proponía un juego visual entre representación y disolución, entre figura y materia, donde las imágenes aparecen muchas veces esbozadas, casi sobrepasadas por los planos de las tintas de colores vibrantes o por las rugosidades, nudos y vetas de la superficie de la madera en tanto significantes expresivos. Con estas xilografías-collage modernistas, Seoane proponía una clara variante, tanto en el sentido técnico como en el de las imágenes que presentaba, respecto del registro ortodoxo del grabado en madera en función de la ilustración literaria, un tipo de práctica que, a la vez, el artista continuó desplegando contemporáneamente, tal como se pone en evidencia con sus estampas para Sobre los ángeles, de Rafael Alberti, Llanto para Ignacio Sánchez Mejía de Federico García Lorca, El diario poético de Miguel de Unamuno o los 32 refranes criollos publicados por Eudeba, que también se encuentran en el patrimonio gráfico de este museo.

\footnotetext{
4 Seoane nació en 1910 en Buenos Aires, en el seno de una familia gallega inmigrante. De muy niño, vivió en Galicia, donde se formó profesionalmente; con el estallido de la Guerra Civil Española, retornó a Argentina y desde entonces y hasta su muerte, en 1979, desarrolló sus actividades desde ese doble anclaje cultural y nacional.

5 Con anterioridad, sólo una vez había expuesto individualmente en un espacio oficial argentino, con su muestra en el Museo Municipal de Bellas Artes Dr. Genaro Pérez de la ciudad de Córdoba. Posteriormente, el Museo de Arte Moderno de Buenos Aires ha organizado exposiciones de la obra gráfica de Seoane en distintas ocasiones: 1978, 1983, 1988, 2000 y 2010.
}

6 Sur, Buenos Aires, año XII, número 97, octubre de 1942, Pp. II 2 - II 3. 


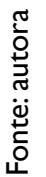

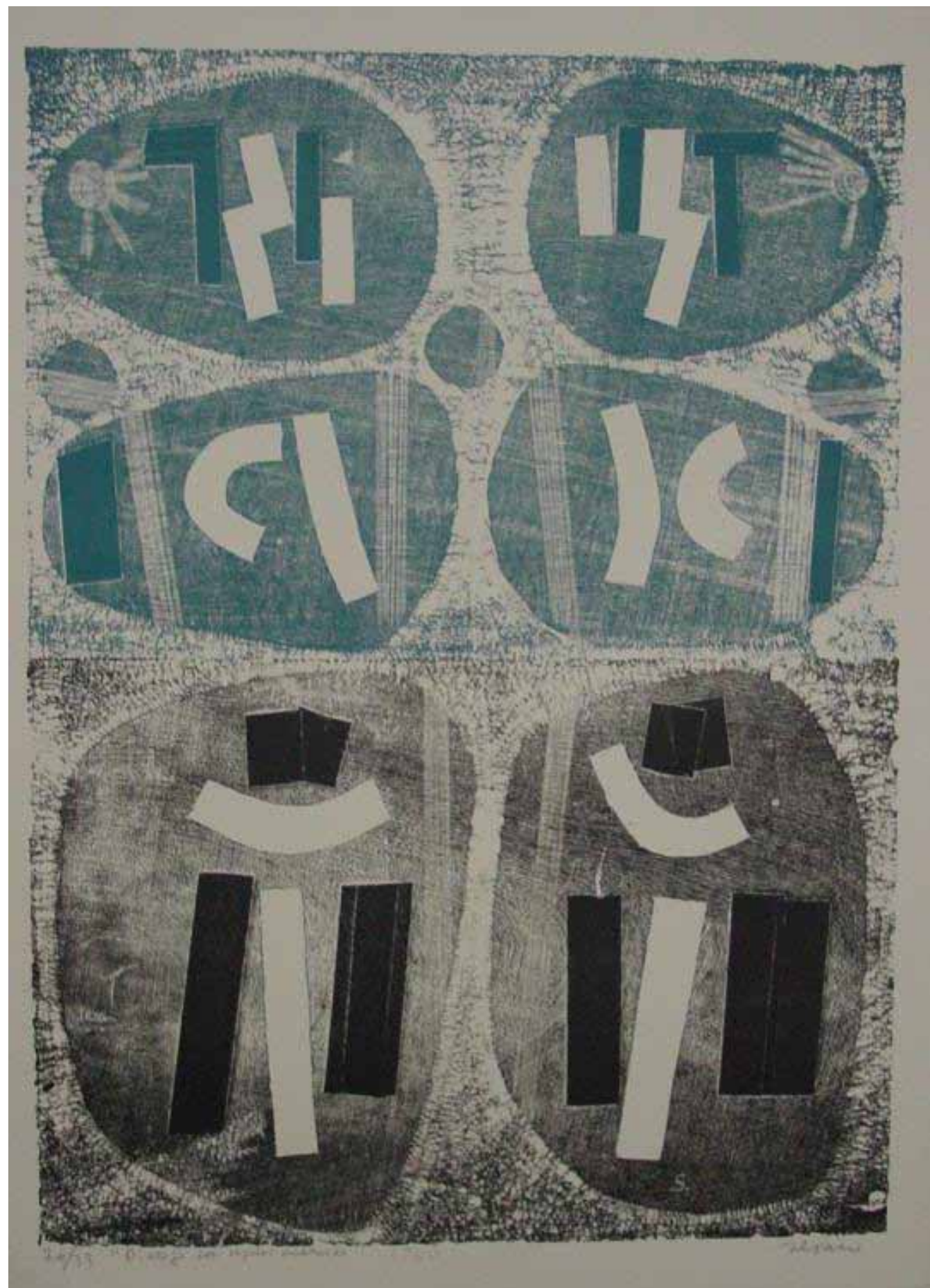

Flg.3. Luis Seoane, Diálogo con signos andando, xilografía con collage, 1958; 

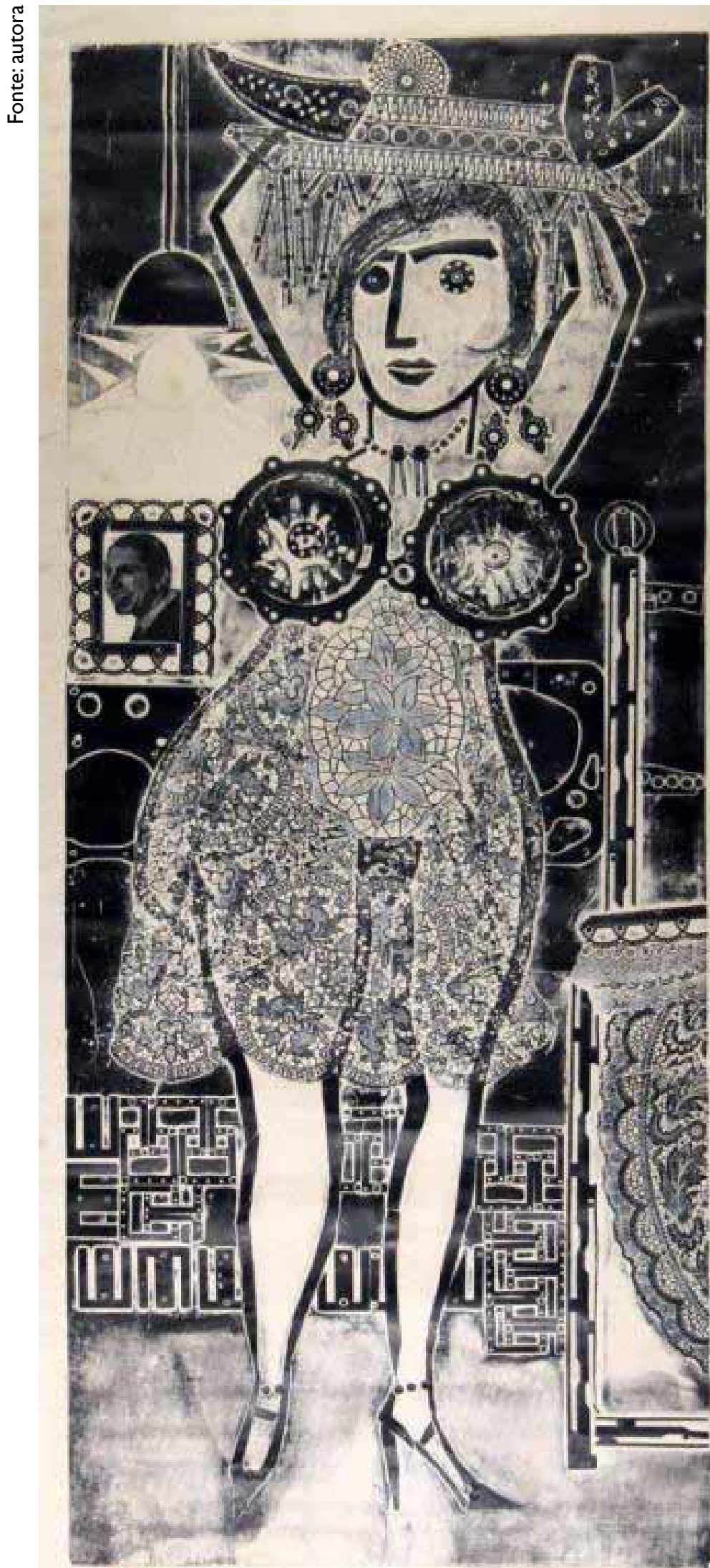

Fig.4.Antonio Berni, Ramona vive su vida, 1963 
EI MAMBA también posee una obra de Antonio Berni que resulta emblemática respecto de la contemporánea redefinición de la histórica xilografía: Ramona vive su vida (fig. 4), una de las estampas de la primera serie sobre el personaje Ramona Montiel desarrollado por ese artista argentino desde el año 1962. En ese conjunto sobre la joven prostituta y sus "amigos", Berni exploró la conjunción de la xilografía, el collage de elementos heterogéneos —unificados a partir de la impresión monocromática-y el leve relieve del papel por la presión de la prensa sobre éste. El artista daba cuerpo al personaje y su entorno a partir de objetos propios de la sociedad de consumo: manteles de plástico que imitaban encajes - un material contemporáneo que simulaba o traducía a un soporte barato cierta idea de refinamiento o de lujo-, botones recargados, recortes de metal perforado con máquinas industriales, piezas metálicas de mecano, marcos de diapositiva. En el caso de Ramona vive su vida, la protagonista de la serie aparece representada sola, en el interior de una habitación donde se perfila algún mueble, la decoración de un friso y una lámpara de aire picassiano debajo de la cual cuelga una foto del célebre cantante de tangos Carlos Gardel; la presencia de la imagen del cantante - surgida de un clisé metálico de fotograbado incluido en la matriz de madera - alude a los posters y fotos de los ídolos de masas impresas de forma industrial, introduciendo así una alusión a la cultura popular.

Esta obra formó parte de la exposición de Berni en el MAM en agosto de 1963, la cual estuvo integrada por treinta estampas y tres tacos xilográficos o matrices. ${ }^{7}$ La primera muestra de grabados del artista llevada a cabo en esta institución ${ }^{8}$ conmocionó la escena porteña. Además del impacto que producía el gran tamaño de las estampas y las imágenes de la serie de xilocollages de Ramona Montiel y sus "amigos", intervino otro factor simbólico: se trataba de la presentación en Buenos Aires de las xilografías sobre Juanito Laguna distinguidas en la Bienal de Venecia de 1962 con el Gran Premio en Grabado y Dibujo, y que el público porteño había conocido hasta ese momento solamente a través de reproducciones en la prensa. Según Parpagnoli, la muestra "implicaba la bienvenida que le daba Buenos Aires al gran artista argentino después de su actuación de resonancia mundial".9

El éxito de Berni en la Biennale resulta el caso más resonante de los artistas argentinos que participaron en distintos escenarios internacionales dedicados en esos tiempos a la disciplina. Como punto destacado dentro de un dinámico circuito de exhibición internacional, artistas de las más variadas procedencias geográficas también encontraron en el MAM un ámbito expositivo recurrente. La sucesión de muestras de gráfica internacional, iniciada en los años sesenta con exposiciones procedentes de Chile, Holanda y Brasil, ${ }^{10}$

7 La exhibición de las matrices para la impresión resultaba un hecho anómalo para los criterios del momento, pues se consideraba que "la obra" era la estampa en sí, y no el soporte que la originaba. La presentación de los tacos con collage remarcaba la originalidad y el virtuosismo técnico del procedimiento creado por Berni.

8 En 1999 se volvió a presentar en el MAMBA un destacado y más extenso conjunto gráfico de Berni, luego exhibido en otros espacios museográficos.

9 "Berni en el Museo de Arte Moderno", La Prensa (Buenos Aires) (7-8-1963). Sobre los grabados de Antonio Berni, cf. Dolinko (20I2).

I0 Pinturas y grabados chilenos de hoy (1962) incluyó, entre otros, estampas de Nemesio Antúnez, José Balmes, Gracia Barrios, Roser Bru, Dinora Doudchinsky, Julio Escámez y Juan Bernal Ponce; Grabadores contemporáneos de Holanda (1963) presentó, por ejemplo, a Karel Appel, Corneille, Anton Heyboer, Ger Lataster, Pierre van Soest y CarelVisser; muchas de las obras allí presentadas pasaron luego a formar parte del patrimonio del museo. En la muestra Artistas brasileños contemporáneos (1966) hubo obra gráfica de Edith Behring, Roberto De Lamonica, Anna Bella Geiger, Rossini Pérez,Arthur Luiz Piza, entre otros. 
fue especialmente fluida en las dos décadas siguientes con la presentación de conjuntos de grabados rumanos, polacos, australianos, norteamericanos, alemanes, húngaros, daneses, holandeses, suizos, israelíes, japoneses, italianos, chinos, búlgaros. En 1988 se realizó la exposición Buenos Aires-Praga-Buenos Aires, punto de origen para la donación de un importante y variado conjunto de grabados realizados en esa década por artistas checoslovacos; este corpus, heterogéneo desde el punto de vista de sus vertientes iconográficas y expresivas, aparece unificado por la común destreza de realización de los numerosos artistas y su dominio de las diferentes técnicas gráficas, especialmente en el grabado sobre metal. Dentro de las exposiciones individuales de artistas extranjeros llevadas a cabo en la institución es importante destacar las del paraguayo Carlos Colombino (en 1969), el norteamericano Robert Rauschenberg (en 1977), la brasileña Fayga Ostrower (en 1986), el francés Pierre Soulages (en 1989), el alemán Joseph Beuys (en 1993) o el español Antoni Muntadas (en 1997 y 2002), entre otras.

Las fotoserigrafías de Muntadas como Brasil... tudo bem, tudo bom I (1999) o aquella correspondiente a la serie Portraits (1995) — fragmento de rostro que posibilita un fluido diálogo visual con la contemporánea estampa Phil Spitbite en la que Chuck Close reedita la imagen de Philip Glass- corresponden a las obras de artistas extranjeros más recientes dentro de esta colección del museo. Junto a los numerosos grabados procedentes de Europa del Este, se destaca en este apartado la obra gráfica de artistas ligados al modernismo europeo del siglo xx. Los nombres de Kandinsky, Picasso, Léger, Arp, Bill, Corneille, Herbin, Hartung, Vasarely, entre otros, se suman al patrimonio del museo a través de sus aguafuertes, serigrafías y, sobre todo, litografías. Resulta significativo que tantos artistas destacados del siglo pasado abrevaran en la experiencia gráfica. Tanto por el impulso dado por los ateliers como por la acción de galerías de arte especializadas, las estampas de estos artistas -más accesibles, tanto en términos económicos como materiales, debido al soporte de papel de fácil traslado- circularon en forma fluida entre distintos países especialmente a partir de los años cincuenta, y forman parte de distintas colecciones que se iniciaron o consolidaron en esos tiempos de un progresivo afianzamiento de la sociedad de consumo.

En esos mismos años, el grabado argentino comenzó a incorporarse en forma progresiva a la oferta de las galerías de arte locales. Éstas eran un nuevo espacio de visibilidad para este tipo de producción respecto de una tradición local construida desde las primeras décadas del siglo xx, en la que las vías de circulación más afianzadas resultaban los Salones oficiales -en sus diferentes modalidades: nacional, provinciales, municipales- que brindaban premios para la disciplina, y los concursos organizados por distintas agrupaciones como la Sociedad de Acuarelistas y Grabadores o la Sociedad Argentina de Artistas Plásticos. Otro espacio de circulación novedoso desde la posguerra fue el de los certámenes internacionales; tanto en el caso de muchos artistas argentinos como de otros países, su obra gráfica también se difundió y obtuvo "beneficios simbólicos" a partir de la exhibición y premiación en este circuito. Si entre los reconocimientos asignados en la Bienal de Venecia se encontraba un premio para esta especialidad, " también desde la posguerra se articuló un circuito de concursos dedicados exclusivamente al

I I Obtenidos, por ejemplo, por Miró o Chagall, artistas presentes en esta colección del MAMBA a través de litografías. 
grabado, como las pioneras Bianco y Nero en Suiza desde 1950 o la Bienal de Ljubljana iniciada en 1955, las bienales desarrolladas en Latinoamérica - Santiago de Chile, San Juan de Puerto Rico, Cali-, o las de Bradford o Florencia iniciadas en 1968. Precisamente en ese año se desarrollaron en Buenos Aires certámenes de grabado que daban cuenta del impulso que había cobrado esta producción en el campo local, como la Primera Bienal Internacional de Grabado organizada por el Club de la Estampa de Buenos Aires -agrupación de la cual el MAMBA también posee materiales en su patrimonio: una carpeta de litografías y xilografías - o la primera edición del Salón Swift, patrocinado por el frigorífico de capitales norteamericanos. Precisamente, este museo fue escenario para dicha competición de obras de la nueva generación de grabadores. ${ }^{12}$

Un ejemplo del sentido experimental puesto en juego en algunas propuestas gráficas de esos momentos lo proporciona Swift en Swift de Juan Carlos Romero, ganadora del premio mayor en el Tercer Salón Swift (1970) y presentada en el MAM. En momentos en que la empresa auspiciante del certamen realizaba masivas suspensiones de sus empleados y obreros, Romero denunciaba a partir de un enfoque conceptual la violenta acción patronal: desde una selección de párrafos de Los viajes de Gulliver de Jonathan Swift que aludían a la destrucción y los mecanismos de dominación del poder, refería al conflicto en que se encontraban sumidos los obreros. Las frases que conforman la obra están presentadas como un continuum textual estarcido sobre extensos papeles de afiche publicitario (Dolinko, 2012; Romero, Davis y Longoni, 2010).

Esta obra marcó el inicio de un crescendo del aspecto político en la obra de Romero, quien continuó indagando en esta línea, por ejemplo, en su instalación de 1973 Violencia en el CAYC dirigido por Jorge Glusberg, en donde trabajó a partir de diversos soportes de la gráfica masiva, y para la cual realizó carteles en offset con la palabra "violencia". También Marie Orensanz realizó con esta modalidad de impresión los afiches que conformaron la instalación La Gallareta, realizada junto con Mercedes Esteves en 1969. El museo posee en su colección uno de esos afiches "originales" realizados por Orensanz, a la vez que también un ejemplar de la impresión offset que Romero, revisitando su propuesta setentista, editó en 2000 y presentó en su muestra en el MAMBA de ese año.

Contemporáneamente a estos planteos, Liliana Porter desarrolló una obra gráfica claramente experimental en la que conjugó distintos recursos conceptuales para indagar sobre la noción y los alcances de la obra impresa contemporánea. En 1970, la artista trabajaba a partir de un repertorio de registros sobre el papel —convencional soporte para la impresión- tensado, arrugado, doblado: arrugas reales o representadas, hilos y lanas que tensan superficies, proyección de sombras gráficas que desbordan papeles concretos. Su juego visual y a la vez conceptual en torno a la materialidad de la obra impresa operó subvirtiendo la ortodoxia del grabado y su dimensión artesanal y técnica en función de la transmisión de sus ideas sobre la gráfica. En varias de estas obras desplazaba el código del grabado hacia los márgenes de la imagen: más literalmente, quedaba circunscripto al borde del papel, rehundido por la acción de la prensa sobre la plancha de metal.Aparece también en este corpus el recurso del hilo de lana que, cosido en dos puntos de la hoja, inscribe un eje que tensa el plano del papel blanco y trasmuta el soporte de la obra en superficie de presentación/representación. De este modo, Porter

12 También el MAM fue sede en 1967 del Premio Braque de grabado. 
ya desplegaba entonces una lectura respecto de la relación entre el simulacro, la realidad y el acto de representar esa realidad que prolongaría en toda su obra posterior (Katzenstein, 2003).

Frente a estas prácticas ligadas al conceptualismo, otros artistas se inscribieron en esos mismos años dentro de las corrientes de reivindicación de la imagen figurativa y del beau métier en la realización de la obra artística que, en el caso del grabado, implicó una vertiente ligada fuertemente a la tradición de esta práctica. Obras como Adilardo y la fuga de los calvos de Aída Carballo (fig. 5), o Señora sea bella III de Julio Paz, dan cuenta de las relecturas contemporáneas sobre la representación de la figura humana, en ocasiones atravesadas por la sátira y el humor — como también se mencionó en referencia a la obra de Seguí- y sobre la praxis gráfica contemplada en su dimensión de producción plural (Faccaro, 1977).

Contrariamente a este lineamiento canónico del grabado como obra impresa múltiple, y prolongando la distancia respecto de la noción de serialidad de la gráfica que se inauguró en algunas de las experiencias de principios de los años setenta, en 1985 se llevó a cabo en el MAM la exposición Intuiciones, intenciones, impresiones del que luego sería conocido como Grupo 6 (Marín, 20I2). La presentación conjunta de Alicia Díaz Rinaldi, Matilde Marín y Graciela Zar, entre otras, ${ }^{13}$ era recibida como una muestra "poco convencional" en la que las artistas exploraban diversos soportes de impresión y una expansión, en algunos casos, hacia la tridimensionalidad de la obra. En una nueva etapa de búsquedas gráficas iniciada en esos años, se retomaban algunas de las vías abiertas en los "dorados sesenta", a la vez que se iniciaban otros abordajes a partir de la imbricación de nuevas poéticas, medios y soportes.

Como se ha pretendido trazar en este recorrido, una lectura de la colección de grabados del Museo de Arte Moderno de Buenos Aires posibilita dar buena cuenta de los cambios y permanencias de la obra gráfica del siglo $x \mathbf{x}$, de las idas $y$ vueltas entre un canon gráfico y sus cíclicas transformaciones experimentales. Asimismo, se ha intentado demostrar cómo desde los años sesenta esta institución resultó un espacio clave en el proceso de visibilidad y legitimación simbólica del grabado en el campo artístico local al privilegiar las producciones contemporáneas de los artistas. Recordemos, en este sentido, los casos de las exhibiciones de obra gráfica de los artistas argentinos desplegadas entre los años sesenta y principios de los setenta: distintas propuestas que en esos mismos tiempos conmocionaban la escena del grabado. El museo se constituyó así en un marco institucional sobresaliente para la confirmación de sus búsquedas, poniendo en valor la apertura disciplinar que proponían esas obras.

Alrededor del cambio de siglo se organizaron en el MAMBA nuevas exposiciones de la, ya para entonces, histórica gráfica experimental de Berni (en 1999), Seoane, Romero (ambas en 2000) y Seguí (200I), artistas sobre los que se ha detenido particularmente el presente trabajo. Si las anteriores muestras de esas obras habían implicado la presentación en el museo de una producción contemporánea, su exhibición tres décadas más tarde —como así también (en 2003) la de las heliografías de gran tamaño realizadas por León Ferrari a principios de los años ochenta en Sao Paulo-, implicó una importante operación de revisión historiográfica de algunos de los principales núcleos de renovación de la gráfica en la Argentina.

13 En el patrimonio del MAMBA hay obras de estas artistas. 


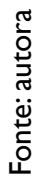

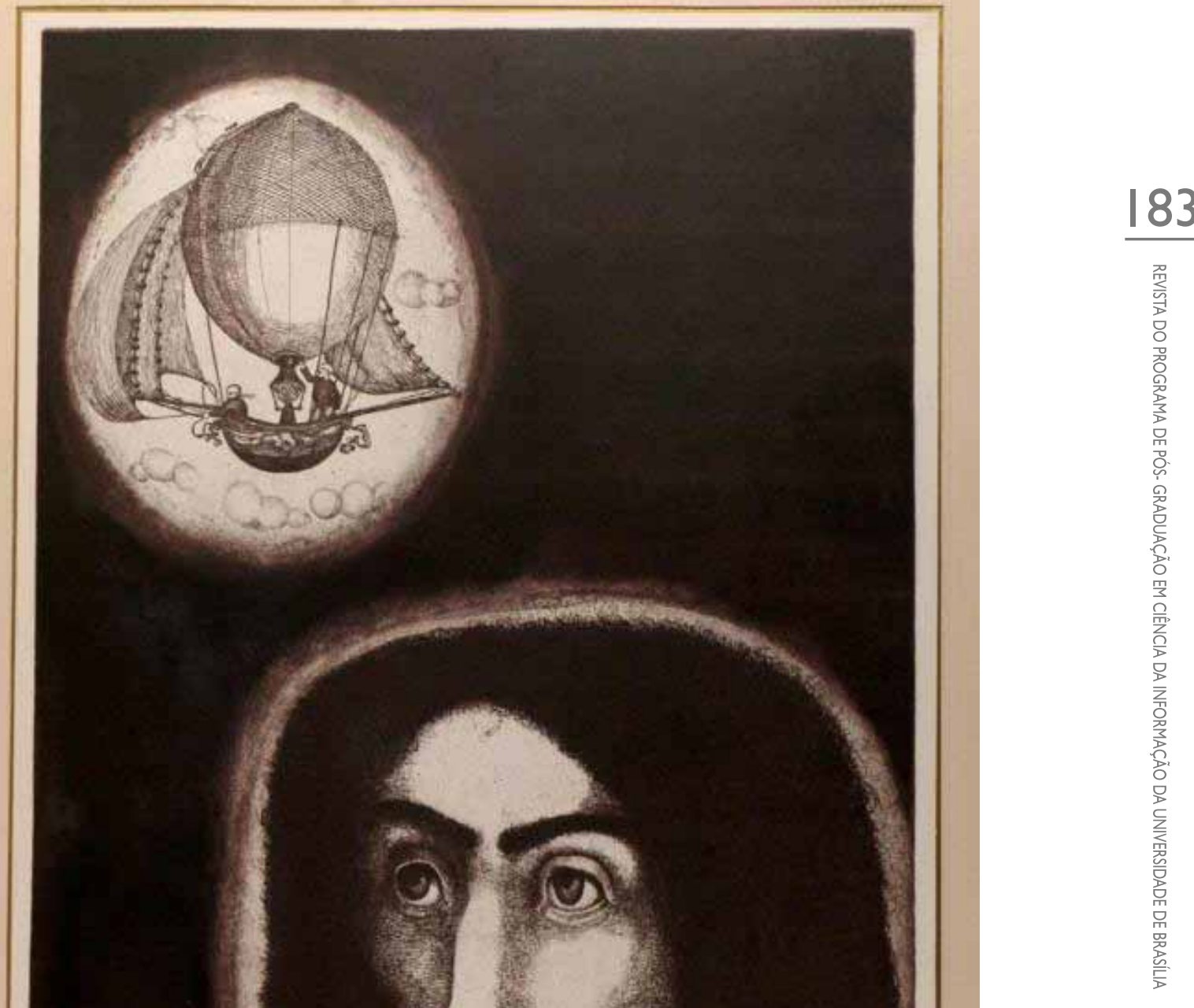

Fig.5. 5 Aída Carballo,Adilardo y la fuga de los calvos, 197I; 
El impacto que continúan proporcionando estas obras evidencia que su presentación como obra "histórica", más que una cristalización del sentido experimental que se desprende de ellas, pone en relieve y confirma su lugar dentro del recorrido del grabado argentino. $Y$ de entre los diversos sentidos que pueden seguirse a partir de los planos y cartografías trazadas en las impresiones de Ferrari se puede pensar, en este marco, que estos proporcionan un buen indicador — tal vez, una buena hoja de ruta - de los múltiples caminos que tomó el grabado en la Argentina: muchas veces intrincados, otras más allanados, pero siempre dinámicos.

\section{Referencias}

AAVV. Museo de Arte Moderno de Buenos Aires. Patrimonio, Buenos Aires, Asociación Amigos del Museo de Arte Moderno, $201 \mathrm{l}$.

BAYÓN, Damián. “La originalidad en la obra gráfica de Antonio Segui'”. Antonio Seguí. Obra gráfica 1948/1992, San Juan de Puerto Rico, Instituto de Cultura Puertorriqueña, 1993.

DOLINKO, Silvia. Arte plural. El grabado entre la tradición y la experimentación (1955-1973), Buenos Aires, Edhasa, 2012.

DOLINKO, Silvia. "El grabado, una producción híbrida como problema para el relato modernista", Crítica cultural, Programa de Pós-Graduação em Ciências da Linguagem da Universidade do Sul de Santa Catarina (UNISUL), volumen 4, número I, 2009a.

DOLINKO, Silvia. "Grabados originales multiplicados en libros y revistas". In: COSTA, Laura Malosetti Costa; GENÉ, Marcela (comps.). Impresiones porteñas.Imagen y palabra en la historia cultural de Buenos Aires. Buenos Aires, Edhasa, $2009 \mathrm{~b}$.

DOLINKO, Silvia (2006), Luis Seoane, xilografías, Santiago de Chile, Centro Cultural de España.

FACCARO, Rosa. "Aída Carballo. El arte de grabar", Foco, Buenos Aires, año I, número 4, 1977.

GARCÍA, María Amalia. El arte abstracto. Intercambios culturales entre Argentina y Brasil, Buenos Aires, Siglo XXI, 201 I.

GUINTA,Andrea.Vanguardia, internacionalismo y política.Arte argentino en los sesenta, Buenos Aires, Paidós, 200I.

KATZENSTEIN, Inés (cur.). Liliana Porter. Fotografía y ficción, Buenos Aires, Centro Cultural Recoleta-Malba, 2003.

MARÍN, Matilde. Discursos gráficos: artistas y grupos de producción gráfica entre 1960 y 1990, Buenos Aires, Fundación Osde, 2012.

ROMERO, Juan Carlos; DAVIS, Fernando; LONGONI, Ana Longoni. Romero, Buenos Aires, Fundación Espigas, 2010. 